\title{
Factors Associated with Prevalence of Malaria Infection among Children under 5 Years of Age in Mozambique: 2015 vs 2018
}

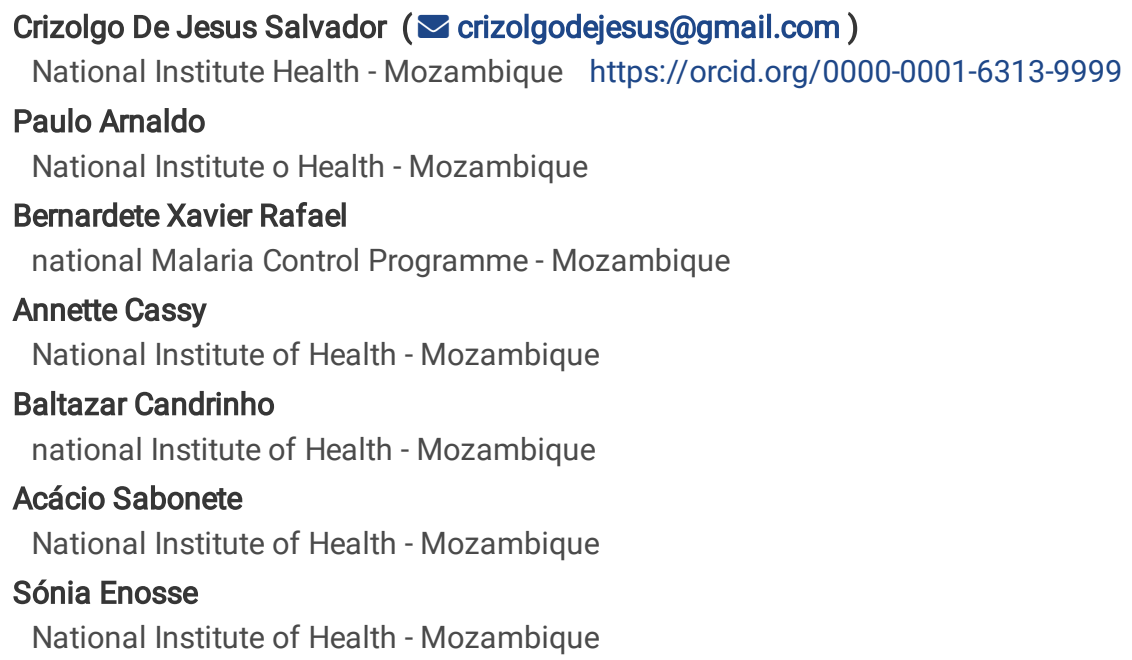

\section{Research}

Keywords: Malaria, P. falciparum, children six to 59 months old, insecticide treated nets, Mozambique

Posted Date: February 4th, 2021

DOI: https://doi.org/10.21203/rs.3.rs-168223/v1

License: (c) (i) This work is licensed under a Creative Commons Attribution 4.0 International License. Read Full License 


\section{Abstract}

Background: Malaria is still a leading cause of morbidity and mortality among children under five years old in Mozambique. In this study we sought to determine the prevalence of malaria infection and its predictors among children six to 59 months old in Mozambique.

Methods: Data from two national malaria indicators surveys in 2015 and 2018 were compared. In both surveys, blood samples were collected among children six to 59 months old to detect Plasmodium falciparum antigen by a rapid diagnostic test, and questionnaires were applied to collect socio-economic, demographic and vector control data from their households. Association of malaria rapid diagnostic test positivity with age, gender, residence, region, use of a vector control intervention, mother's level of education and wealth index was assessed by logistic regression, using both univariate and multivariate analysis. A complex sampling logistic regression model was used to identify factors associated with malaria infection with estimated adjusted odds ratio and respective $95 \%$ confidence intervals.

Results: A total of 9,068 children were tested for malaria infection of which 4,640 were in 2015 and 4,428 in 2018 . The prevalence of malaria infection was $40.2 \%$ and $38.9 \%$ in 2015 and 2018, respectively. From 2015 to 2018, insecticide-treated nets ownership increased from $72.3 \%$ to $90.2 \%(p<0.001)$ and insecticide-treated nets use increased from $45.5 \%$ to $72.4 \%$ in children under the age of 5 years $(p<0.001)$. In multivariate analysis, malaria infection was associated with region (north and central regions) and rural area for both surveys. Living in households with a wealth quintile lower than the wealthiest was associated with an increased odds of malaria infection $(p<0.001)$. Maternal level of education and absence of an insecticide-treated net in the household were associated with malaria infection in 2015 ( $p<0.001)$ but not in 2018. Malaria infection was associated with age older than 12 months in 2015 and with age 24-35 months and 48-59 months in2018.

Conclusions: Although insecticide-treated nets ownership and use have increased between the two surveys, prevalence of malaria infection remained stagnant. The main predictors of malaria infection were region, place of residence and socioeconomic status, underscoring the importance of broader developmental and socioeconomic factors on malaria prevalence.

\section{Background}

Malaria is still a leading cause of morbidity and mortality among children under five years of age around the world. In 2018, 228 million cases and 405,000 deaths from malaria were reported globally. The sub-Saharan Africa region accounted for $93 \%$ of the cases and $94 \%$ of the deaths. Mozambique contributed $4 \%$ of the global malaria case burden (1). The distribution of malaria prevalence in Mozambique is heterogeneous, with a higher prevalence in the northern and central regions compared to the southern region (2). The National Malaria Control Program (NMCP) of Mozambique developed the 2017-2022 National Strategic Plan to implement and monitor interventions for malaria control. In order to reduce the burden of malaria in the country, the NMCP is investing resources in a combination of vector control and case management interventions (3). However, the impact of the interventions on high risk populations and areas of high prevalence is not yet known. Understanding the factors associated with the prevalence of malaria infection and its distribution is important to improve the planning of national and sub-national malaria control strategies.

Previous global research on the factors associated with malaria prevalence and distribution have shown varied results. Some studies have shown that access and use of prevention strategies such as insecticide treated nets (ITNs) and indoor residual spray (IRS) reduced malaria prevalence $(4,5)$ while in others the use of these strategies have shown no significant impact $(6)$. Higher socioeconomic and educational status have also been indicated as protective by some authors (7) while others found no relation (8). In this analysis we sought to determine the prevalence of malaria infections and its predictors among children six to fifty-nine months old in Mozambique by comparing the 2015 Malaria, HIV/AIDS, and Immunization Indicator Survey (IMASIDA) and the 2018 Malaria Indicator Survey (MIS). The analysis will provide information on the coverage of interventions for malaria control and factors associated to the prevalence of malaria. These information can support the NMCP to strengthen the planning malaria control interventions.

\section{Methods}

\section{Study setting}

The analysis is based on two nation-wide surveys. Mozambique is divided in three regions, northern, central, and southern. The northern region includes the provinces of Niassa, Cabo Delgado and Nampula, and the central region includes the provinces of Tete, Zambézia, Manica and Sofala, and the southern region includes the provinces of Inhambane, Gaza, Maputo and Maputo City. Typically, Mozambique has a tropical climate with two distinct seasons: a hot and humid season from October to March and a dry and cool season from April to September, although there are variations depending on the region and altitude. Malaria transmission is higher in the hot and humid season due to the abundance of water and vegetation, which favours breeding of Anopheles mosquitoes. P. falciparum accounts for $90 \%$ of all malaria infections (9). 


\section{Study Design and data source}

We conducted a retrospective analysis of data from two community-based surveys conducted in 2015 and 2018 . The IMASIDA was conducted from June to September in 2015, while the MIS was conducted from March to June 2018. For both surveys, the sampling was representative nationally, for rural and urban areas, and at the provincial level. Households were selected using data from the General Population and Housing Census 2007 (RGPH 2007). In the first stage of sampling, Enumeration Areas (EAs) were selected from the total EA outlined in the RGPH 2007, with probability-proportional-to-size, in which some were located in urban areas and others in rural areas. A total of 307 EAs, in which 134 (43.6\%) were urban, were selected for the IMASIDA 2015 and 224 EAs, in which 92 (41.1\%) were urban, were selected for the MIS 2018. In the second sampling stage, all households within the EA were listed followed by random selection of households. A total of 24 and 28 households per EA were selected for the IMASIDA 2015 and for the MIS 2018, respectively. In total, 7,368 households were selected in IMASIDA 2015 and 6,279 households were selected in MIS 2018. Women aged 15-49 years and children aged 6-59 months, who were habitually resident or had spent the night before the survey in the household were eligible for interview and malaria testing respectively. For the IMASIDA, responses rates were $97.6 \%$ for selected households and $94.5 \%$ for eligible women; for the MIS 2018 , response rates were $99.0 \%$ for households and $98.3 \%$ for eligible women.

\section{Data collection}

For both surveys data was collected from three sources: i) a household questionnaire was used to collect information to determine the household wealth index, information of the household owner-ship and use of insecticide treated nets (ITN), and exposure to indoor residual spraying (IRS); ii) a questionnaire addressed to women aged 15-49 was used to collect information on age, residence history, educational level, intermittent preventive treatment of malaria during pregnancy, use of ITN, treatment of malaria in children under 5 years of age and knowledge of malaria; iii) a biomarkers questionnaire was used to record the results of the malaria and anaemia tests in children $6-59$ months of age.

\section{Malaria testing}

Malaria tests were performed using capillary blood samples taken from the fingers or heels of included children. In the IMASIDA 2015, malaria testing was performed using rapid diagnosis test (RDT) SD Bioline Malaria Ag Pf and Pv (Abbott) to detect $P$. falciparum and P.vivax antigens while in the MIS 2018 the RDT was SD Bioline Malaria Ag Pf (Abbott) which detects only the P. falciparum antigen.

\section{Statistical analysis}

To prepare the data for analysis, the individual members (PR) datasets from both surveys were merged into one dataset. Special (svy) survey commands were used to account for complex multilevel survey design. Data were weighted to account for the differential selection probabilities at the EA, household and individual levels. Only weighted survey data are presented in this manuscript. Socio-economic, demographic and vector control characteristics were compared between 2015 and 2018 using $t$-student test. Logistic regression was used to evaluate factors associated with presence of Plasmodium sp antigen as detected by RDT among children under 5 years of age (dependent variable). The independent variables included: age; gender; residence (urban vs rural); region (southern, central or northern); use of ITNs; IRS in the past 6 months; highest education level attained by the mother; and wealth index. Multivariate complex sampling logistic regression was used to identify factors associated with malaria infection, with estimated adjusted odds ratio (AOR) and respective $95 \%$ confidence intervals (Cl). All statistical analyses were performed using Stata, version 15 (Stata Corporation, College Station, Texas).

\section{Ethical considerations}

For both surveys, ethical approval was obtained from the Mozambique National Bioethics Committee for Health (CNBS) prior to data collection, IMASIDA 2015 (42/CNBS/2014) and MIS 2018 (69/CNBS/18). Written informed consent was obtained from study participants. Parental consent was also provided for all children who were tested for malaria and anaemia.

\section{Results}

\section{General characteristics of study participants and prevalence of malaria infection}

A total of 9,068 children under the age of five years were tested for malaria infection, of which 4,640 (51.2\%) from the 2015 survey and 4,428 (48.8\%) from the 2018 survey. Table 1 shows the socio-demographic characteristics of study participants for both surveys; no significant differences were found. The proportion of households who owned at least one ITN was significantly higher in 2018 , with $72.3 \%$ in 2015 and $90.2 \%$ in $2018(p<0.001)$. Similarly, the proportion of children under 5 years who reported sleeping under ITN the night before the survey increased from $45.5 \%$ in 2015 to $72.4 \%$ in 2018 ( $p<0.001)$. 
Table 1

Demographic characteristics of children 6-59 months old and vector control interventions indicators in two surveys in Mozambique, 2015 and 2018.

\begin{tabular}{|c|c|c|c|c|c|}
\hline \multirow[t]{3}{*}{ Variable } & \multirow{2}{*}{\multicolumn{2}{|c|}{$\begin{array}{l}\text { IMASIDA } 2015 \\
\mathrm{~N}=4640\end{array}$}} & \multirow{2}{*}{\multicolumn{2}{|c|}{$\begin{array}{l}\text { MIS } 2018 \\
N=4428\end{array}$}} & \multirow[t]{3}{*}{$P$ value } \\
\hline & & & & & \\
\hline & $\mathbf{n}$ & $\%(95 \% \mathrm{Cl})$ & $\mathbf{n}$ & $\%(95 \% \mathrm{Cl})$ & \\
\hline \multicolumn{6}{|l|}{ Malaria infection } \\
\hline Negative & 2773 & $59.8(55.6-63.8)$ & 2705 & $61.1(56.3-65.7)$ & \multirow[t]{2}{*}{0.696} \\
\hline Positive & 1867 & $40.2(36.2-44.4)$ & 1723 & $38.9(34.3-43.7)$ & \\
\hline \multicolumn{6}{|l|}{ Gender } \\
\hline Male & 2312 & 49.8 (48.0-51.7) & 2248 & $50.8(48.4-53.1)$ & \multirow[t]{2}{*}{0.531} \\
\hline Female & 2328 & $50.2(48.3-52.0)$ & 2179 & $49.2(46.9-51.6)$ & \\
\hline \multicolumn{6}{|c|}{ Child's age in months } \\
\hline $6-11$ & 492 & $10.6(9.6-11.7)$ & 526 & $11.9(10.6-13.2)$ & \multirow[t]{5}{*}{0.243} \\
\hline $12-23$ & 1073 & $23.1(21.9-23.4)$ & 967 & $21.8(20.1-23.6)$ & \\
\hline $24-35$ & 1020 & $22.0(20.6-24.6)$ & 988 & $22.3(20.5-24.2)$ & \\
\hline $36-47$ & 1069 & $23.0(21.6-24.6)$ & 953 & $21.5(19.9-23.2)$ & \\
\hline $48-59$ & 986 & $21.3(19.9-22.7)$ & 994 & $22.5(21.0-24.0)$ & \\
\hline \multicolumn{6}{|c|}{ Maternal education level } \\
\hline No education & 1272 & $30.2(26.9-33.8)$ & 1005 & $26.1(22.2-30.5)$ & \multirow[t]{3}{*}{0.062} \\
\hline Primary & 2343 & $55.7(52.4-58.9)$ & 2085 & $54.2(49.6-58.8)$ & \\
\hline Secondary/Higher & 595 & $14.1(12.2-16.4)$ & 755 & $19.6(15.1-25.1)$ & \\
\hline \multicolumn{6}{|l|}{ Region } \\
\hline North & 1775 & $38.25(32.9-44.0)$ & 1600 & $36.2(29.0-44.0)$ & \multirow[t]{3}{*}{0.436} \\
\hline Central & 1845 & $39.8(34.5-45.3)$ & 2044 & $46.2(38.4-54.2)$ & \\
\hline Southern & 1020 & $22.0(18.4-26.0)$ & 783 & $17.7(14.0-22.1)$ & \\
\hline \multicolumn{6}{|l|}{ Place of residence } \\
\hline Rural & 3505 & $75.5(71.1-79.5)$ & 3238 & 73.1 (67.0-78.5) & \multirow[t]{2}{*}{0.598} \\
\hline Urban & 1135 & $24.5(20.6-28.9)$ & 1189 & $26.9(21.5-33.0)$ & \\
\hline \multicolumn{6}{|l|}{ Wealth Index } \\
\hline Poorest & 1099 & $23.7(21.0-26.6)$ & 1058 & $23.9(20.0-26.1)$ & \multirow[t]{5}{*}{0.989} \\
\hline Poorer & 1051 & $22.6(20.2-25.3)$ & 1031 & $23.3(20.2-26.7)$ & \\
\hline Middle & 984 & $21.2(18.7-23.9)$ & 913 & $20.6(17.6-24.0)$ & \\
\hline Richer & 873 & $18.8(16.3-21.7)$ & 834 & $18.8(15.7-22.4)$ & \\
\hline Richest & 633 & $13.6(11.3-16.3)$ & 591 & $13.4(10.7-16.5)$ & \\
\hline \multicolumn{6}{|c|}{ Household has at least one ITN } \\
\hline Yes & 3353 & $72.3(68.9-75.4)$ & 3996 & $90.2(87.4-92.5)$ & \multirow[t]{2}{*}{$<0.001$} \\
\hline No & 1287 & $27.7(24.6-31.1)$ & 432 & $9.8(7.5-12.6)$ & \\
\hline \multicolumn{6}{|c|}{ Child under 5 slept under LLIN } \\
\hline Yes & 2110 & $45.5(42.4-48.6)$ & 3204 & $72.4(69.2-75.3)$ & $<0.001$ \\
\hline
\end{tabular}




\begin{tabular}{|c|c|c|c|c|c|}
\hline \multirow[t]{3}{*}{ Variable } & \multirow{2}{*}{\multicolumn{2}{|c|}{$\begin{array}{l}\text { IMASIDA } 2015 \\
\mathrm{~N}=4640\end{array}$}} & \multirow{2}{*}{\multicolumn{2}{|c|}{$\begin{array}{l}\text { MIS } 2018 \\
N=4428\end{array}$}} & \multirow[t]{3}{*}{$P$ value } \\
\hline & & & & & \\
\hline & $\mathrm{n}$ & $\%(95 \% \mathrm{Cl})$ & $\mathbf{n}$ & $\%(95 \% \mathrm{Cl})$ & \\
\hline No & 2530 & $54.5(51.4-57.7)$ & 1224 & $27.6(24.7-30.8)$ & \\
\hline \multicolumn{6}{|l|}{ IRS } \\
\hline Yes & 594 & $12.8(10.2-16.0)$ & 680 & $77.0(73.1-80.4)$ & \multirow[t]{3}{*}{$<0.001$} \\
\hline No & 3987 & $86.0(82.6-88.8)$ & 200 & $22.6(19.2-26.5)$ & \\
\hline Don't know & 57 & $1.2(0.1-1.7)$ & 4 & $0.4(0.0-1.2)$ & \\
\hline
\end{tabular}

The overall prevalence of malaria infection was $40 \%$ in 2015 and 39\% in 2018 (Table 1). Changes in malaria infection prevalence were observed in some provinces from 2015 to 2018. In the province of Cabo Delgado, the prevalence of malaria infection increased from 29.4$57.3 \%$ while in the province of Zambézia the prevalence of malaria infection decreased from $67.9-44.3 \%$ (Fig. 1).

\section{Analysis of factors associated with malaria infection among children under 5 years of age}

As shown in Tables 2 and 3, in the bivariate analysis of both surveys malaria infection was associated with living in northern or central region, living in rural areas, mother's low level of education and low household wealth $(p<0.05)$. No ITN ownership was associated with malaria infection, in the 2015 survey, while age $24-35$ months and 48-59 months were associated with malaria infection in the 2018 survey $(p<0.05)$. 
Table 2

Logistic regression analysis of factors associated with malaria parasitaemia in children 6-59 months old in Mozambique in 2015 IMASIDA

\begin{tabular}{|c|c|c|c|c|}
\hline \multirow[t]{2}{*}{ Variable } & \multicolumn{2}{|c|}{ Bi-variable analysis } & \multicolumn{2}{|c|}{ Multivariable analysis } \\
\hline & OR(95\% Cl) & p-value & AOR $(95 \% \mathrm{Cl})$ & p-value \\
\hline \multicolumn{5}{|l|}{ Gender } \\
\hline Male & 1 & & 1 & \\
\hline Female & $0.9\left(0.8 \_1.1\right)$ & 0.259 & 1.0(08-1.1) & 0.529 \\
\hline \multicolumn{5}{|c|}{ Child's age in months } \\
\hline $6-11$ & 1 & & 1 & \\
\hline $12-23$ & $1.4(1.1-1.9)$ & 0.018 & $1.6(1.1-2.0)$ & 0.015 \\
\hline $24-35$ & $1.8(1.4-2.4)$ & $<0.001$ & $2.1(1.6-2.9)$ & $<0.001$ \\
\hline $36-47$ & $1.6(1.2-2.1)$ & 0.003 & $1.8(1.3-2.4)$ & 0.001 \\
\hline $48-59$ & $1.7(1.3-2.3)$ & $<0.001$ & $2.0(1.5-2.6)$ & $<0.001$ \\
\hline \multicolumn{5}{|c|}{ Mother's education level } \\
\hline Secondary/Higher & 1 & & 1 & \\
\hline No education & $4.7(3.0-7.5)$ & $<0.001$ & $1.6(1.1-2.3)$ & 0.028 \\
\hline Primary & $3.7(2.5-5.4)$ & $<0.001$ & $1.5(1.1-2.1)$ & 0.007 \\
\hline \multicolumn{5}{|l|}{ Region } \\
\hline Southern & 1 & & 1 & \\
\hline North & $7.1(4.6-10.8)$ & $<0.001$ & $3.5(2.1-5.7)$ & $<0.001$ \\
\hline Central & $4.3(2.8-6.6)$ & $<0.001$ & $2.1(1.3-3.4)$ & 0.002 \\
\hline \multicolumn{5}{|c|}{ Location of residence } \\
\hline Urban & 1 & & 1 & \\
\hline Rural & $3.7(2.3-5.9)$ & $<0.001$ & $1.8(1.1-3.0)$ & 0.022 \\
\hline \multicolumn{5}{|l|}{ Wealth index } \\
\hline Richest & 1 & & 1 & \\
\hline Richer & $4.0(2.7-6.0)$ & $<0.001$ & $2.8(1.8-4.3)$ & $<0.001$ \\
\hline Middle & $7.6(4.9-11.9)$ & $<0.001$ & $3.6(2.1-6.3)$ & $<0.001$ \\
\hline Poorer & $14.6(9.2-23.0)$ & $<0.001$ & $5.6(3.3-9.7)$ & $<0.001$ \\
\hline Poorest & $19.0(12.1-29.8)$ & $<0.001$ & $6.8(4.0-11.8)$ & $<0.001$ \\
\hline \multicolumn{5}{|c|}{ Household with child $<5$ which has at least one ITN } \\
\hline Yes & 1 & & 1 & \\
\hline No & $1.5(1.2-1.9)$ & $<0.001$ & $1.3(1.0-1.6)$ & 0.033 \\
\hline \multicolumn{5}{|c|}{ Child $<5$ slept under ITN last night } \\
\hline Yes & 1 & & 1 & \\
\hline No & $1.0(0.8-1.3)$ & 0.854 & $0.8(0.7-1.1)$ & 0.140 \\
\hline \multicolumn{5}{|l|}{ IRS } \\
\hline Yes & 1 & & 1 & \\
\hline No & $1.0(0.6-1.7)$ & 0.993 & $0.5(0.3-1.0)$ & 0.042 \\
\hline
\end{tabular}


Table 3

Logistic regression analysis of factors associated with malaria parasitaemia in children $6-59$ months old in Mozambique, MIS 2018.

\begin{tabular}{|c|c|c|c|c|}
\hline \multirow[t]{2}{*}{ Variable } & \multicolumn{2}{|l|}{ Bi-variable analysis } & \multicolumn{2}{|c|}{ Multivariable analysis } \\
\hline & OR $(95 \% \mathrm{Cl})$ & p-value & AOR $(95 \% \mathrm{Cl})$ & p-value \\
\hline \multicolumn{5}{|l|}{ Gender } \\
\hline Male & 1 & & 1 & \\
\hline Female & $0.9(0.8-1.11)$ & 0.414 & $1.0(0.4-1.9)$ & 0.948 \\
\hline \multicolumn{5}{|c|}{ Child's age in months } \\
\hline $6-11$ & 1 & & 1 & \\
\hline $12-23$ & $1.2(0.8-1.6$ & 0.340 & $1.3(0.7-2.4)$ & 0.353 \\
\hline $24-35$ & $1.5(1.2-2.0$ & 0.003 & $2.1(1.3-3.5)$ & 0.005 \\
\hline $36-47$ & $1.2(0.9-1.7$ & 0.233 & $1.6(0.7-3.3)$ & 0.219 \\
\hline $48-59$ & $1.4(1.1-1.9$ & 0.020 & $2.1(1.3-3.6)$ & 0.005 \\
\hline \multicolumn{5}{|c|}{ Mother's education level } \\
\hline Secondary/Higher & 1 & & 1 & \\
\hline No education & $6.1(4.0-9.3)$ & $<0.001$ & $1.1(0.4-2.9)$ & 0.817 \\
\hline Primary & $4.1(2.9-5.7)$ & $<0.001$ & $1.7(0.8-3.6)$ & 0.146 \\
\hline \multicolumn{5}{|l|}{ Region } \\
\hline Southern & 1 & & 1 & \\
\hline North & $5.3(3.3-8.5)$ & $<0.001$ & $5.6(2.5-12.9)$ & $<0.001$ \\
\hline Central & $3.4(2.2-5.3)$ & $<0.001$ & $4.3(2.1-9.1)$ & $<0.001$ \\
\hline \multicolumn{5}{|l|}{ Local of residence } \\
\hline Urban & 1 & & 1 & \\
\hline Rural & $3.8(2.3-6.4)$ & $<0.001$ & $2.3(1.2-4.5)$ & 0.016 \\
\hline \multicolumn{5}{|l|}{ Wealth index } \\
\hline Richest & 1 & & 1 & \\
\hline Richer & $8.9(5.0-15.8)$ & $<0.001$ & 2. $0(0.8-5.2)$ & 0.135 \\
\hline Middle & $24.4(13.8-43.2)$ & $<0.001$ & $5.0(2.1-12.0)$ & $<0.001$ \\
\hline Poorer & $36.0(19.9-65.1)$ & $<0.001$ & $4.1(1.8-9.4)$ & $<0.001$ \\
\hline Poorest & $47.5(27.1-83.2)$ & $<0.001$ & $5.4(2.1-13.8)$ & $<0.001$ \\
\hline \multicolumn{5}{|c|}{ Household with child $<5$ which has at list one ITN } \\
\hline Yes & 1 & & 1 & \\
\hline No & $1.5(1.0-2.3)$ & 0.042 & $0.5(0.2-1.4)$ & 0.172 \\
\hline \multicolumn{5}{|c|}{ Child $<5$ slept under ITN last night } \\
\hline Yes & 1 & & 1 & \\
\hline No & $0.9(0.7-1.2)$ & 0.548 & $1.2(0.7-1.9)$ & 0.508 \\
\hline \multicolumn{5}{|l|}{ IRS } \\
\hline Yes & 1 & & 1 & \\
\hline No & $0.9(0.7-1.4)$ & 0.741 & $1.0(0.6-1.5)$ & 0.821 \\
\hline
\end{tabular}


As shown in Table 2, the results of the 2015 survey multivariate analysis showed that malaria infection was independently associated with children who were 12-23 months old (AOR 1.6; 95\% Cl: 1.1-2.0), 24-35 months old (AOR 2.1; 95\% Cl: 1.6-2.9), 36-47 months old (AOR 1.8; 95\% Cl: 1.3-2.4), 48-59 months old (AOR 2.1; 95\% Cl: 1.5-2.6), living in the northern region (AOR 3.5; 95\% Cl: 2.1-5.7) or central region (AOR $2.1 ; 95 \% \mathrm{Cl}$ : 1.3-3.4), living in rural areas (AOR 1.8; 95\% Cl: 1.1-3.0), mother with no education (AOR 1.6; 95\% Cl: 1.1-2.3) or with primary education level (AOR 1.5; 95\% Cl: 1.1-2.1), no ITN ownership (AOR 1.3; 95\% Cl: 1.0-1.6) and children living in poor households ( $\mathrm{p}<0.05$ ).

As shown in Table 3, the results of 2018 survey multivariate analysis showed that malaria infection was independently associated with age 24-35 months (AOR 2.1; 95\% Cl: 1.3-3.5) or 48-59 months (AOR 2.1; 95\% Cl: 1.3-3.6); living in the central region (AOR 4.3; 95\% Cl: 2.1-9.1) or northern region (AOR 5.6; 95\% Cl: 2.5-12.9); lower household wealth, and living in rural areas (AOR 2.3; 95\% Cl: 1.2-4.5).

\section{Discussion}

The prevalence of malaria parasitemia in Mozambique remained high between the two surveys, $40 \%$ in 2015 and $39 \%$ in 2018 , despite the significant increase in access to ITNs. These findings are similar to some previous studies in countries with high malaria prevalence that reported no malaria reduction after the increase of interventions for malaria control $(4,5)$.

In 2015 the probability of having malaria parasitemia was higher for children living in households with no ITNs, but not in 2018 . Previous studies have reported reduction of malaria parasitemia for children living in household with at least one ITN (10, 11). Yet the finding in 2018, that showed no impact of ITN ownership with malaria parasitemia prevalence, is consistent with some other works $(6,12)$. Others studies conducted in African countries showed that the increase in the ITN ownership does not directly imply the reduction of malaria parasitaemia (5, $13,14)$. There are many possible explanations for this findings, including those related to use. The irregular or inappropriate use of nets and possible exposure of children to mosquito bites during times of day when ITN are not in use could limit their impact (6). Also not all people who own ITN appropriately use it $(15,16)$ and others authors have attributed it to the lack of caregiver's knowledge to use ITN as the many reason for increase malaria parasitemia when the coverage of ITN is high (17). Mosquito insecticide resistance have been reported in Mozambique (18) which could also limit the effectiveness of ITNs to protect against malaria. This information can provide valuable guidance to the NMCP on the need to implement others control measures (6).

Children older than 12 up to 59 months of age had higher odds of testing positive for malaria in 2015 and in 2018 only children aged $24-35$ months and 48-59 months had higher odds of testing positive. These findings are consistent with previous studies $(8,17,19)$. As suggested by other authors older children have higher probability of being bitten by mosquitoes when they are playing in the evening while younger children up to 24 months of age may have lower exposure (17). On the other hand, children in areas of high malaria transmission intensity develop immunity while they grow due to the continuous exposure to infective mosquitoes' bites. This immunity allow older children to harbour parasites without developing malaria symptoms $(20,21)$. These children with no sterilizing immunity can be a reservoir of parasites and drive

malaria transmission Therefore, assessing the prevalence of asymptomatic malaria infections is useful in high transmission areas to guide the designs of interventions for malaria control. Our findings also suggest that other interventions, such as malaria chemoprophylaxis, may be warranted to protect this risk group $(22,23)$.

The results from these two surveys showed that children from poorer families were more likely to test positive for malaria parasitemia compared to those from wealthiest families, a finding common across several African countries $(19,24)$. Other studies in African countries have found that children from higher socioeconomic status families were more likely to sleep under ITN compared to those from lower socioeconomic strata (25). We also found in both surveys that children living in rural areas have higher risk of malaria infection compared to those in urban area $(26,27)$. These results may be explained by previous reports that indicate that rural areas are more suitable breeding grounds for malaria vectors (27). In addition, in rural areas there is a greater probability of finding precarious housing that facilitates the entry of mosquitoes (28). The finding that low wealth index and living in rural areas contribute to increase malaria prevalence shows that the interventions to malaria control cannot be isolated, but must involve improving socio-economic status of the population, like improving environment sanitation to avoid mosquitoes breeding and improving house conditions to avoid biting (6).

In 2015, children from mothers with primary level or no education had higher probability of testing positive for malaria parasitemia. Other studies have reported that lower education as risk factor for malaria parasitemia (29). Mothers with lower education are more likely to develop activities that expose them to mosquito bites and are potentially less informed on how to protect their children from malaria (8).

\section{Limitations Of The Study}

It is important to note, that data collection for the two surveys was performed at slightly different transmission season. This may can mask the impact of malaria control interventions over the years. 


\section{Conclusions}

From 2015 to 2018 the prevalence of malaria parasitemia in children under five years old in Mozambique was stagnant although vector control interventions increased. Our finding show that malaria in Mozambique remains a disease associated to low wealth index and living in rural areas. It suggest that multiple factors like mother's education, wealth index, area of residence must be considered on malaria control interventions, underscoring the importance of integrated responses that address both the malaria vector and the underlying socioeconomic vulnerabilities that facilitate its spread.

\section{Abbreviations}

AOR - Adjusted Odds Ratio; Cl - Confidence Intervals; CNBS - National Bioethics Committee for Health; EA - Enumeration Areas; IMASIDA Malaria, HIV/AIDS and Immunization Indicator Survey; IRS - Indoor Residual Spaying; ITN - Insecticide Treated Nets; MIS - Malaria Indicator Survey; NMCP - National Malaria Control Program; OR - Odds Ratio; RDT - Rapid Diagnosis Test; RGPH - General Population and Housing Census

\section{Declarations}

\section{Ethics approval and consent to participate}

The IMASIDA 2015 and MIS 2018 protocols were approved by the ICF Institutional Review Board and the Mozambican National Bioethics Committee. Prior to enrolment, all eligible participants from both surveys provided written informed consent to participate. The consent was obtained from the mother or guardian of a child. The data were analysed anonymously.

\section{Consent for publication}

Not applicable.

\section{Availability of data and materials}

The datasets analysed on this study are available in the DHS Program, [https://dhsprogram.com/what-we-do/survey-Types/dHs.cfm].

\section{Competing interests}

The authors declare that they have no competing interests.

\section{Funding}

The IMASIDA 2015 was funded by USAID through funds from the President's Malaria Initiative (PMI), Global Fund, WHO, UNICEF, HAI/UW, UNFPA, National Council for Combating HIV and AIDS, through its Common Fund and PEPFAR, through the CDC. The MIS 2018 was funded by USAID through funds from PMI and UNICEF.

\section{Authors' contributions}

SE conceptualization and revision of manuscript; CS writing original manuscript; PA writing and revision of manuscript. AC data analysis and revision of manuscript. BR, AS and BC Revision of manuscript. All authors read and approved the final manuscript.

\section{Acknowledgements}

We would like to thank Eduard Rovira-Vallbona from the Institute of Tropical Medicine, University of Antwerp, Abuchahama Saifodine and Rose Zulliger from US. President's Malaria Initiative, Mozambique for their constructive comments and technical inputs.

\section{References}

1. WHO. World Malaria Report 2019. Geneva: World Health Organization, 2019. World Malaria Report; 2019. 
2. Ministério da Saúde (MISAU) IN de E (INE) e II (ICFI). Inquérito Demográfico e de Saúde 2011. Calverton, Maryland, USA: MISAU, INE e ICFI. Março, 2012. 2011;1-38: https://dhsprogram.com/pubs/pdf/FR266/FR266.pdf

3. Direcção Nacional de Saúde pública. Plano Estratégico da Malária. 2017;60. Available from:

http://www.nationalplanningcycles.org/sites/default/files/country_docs/Mozambique/malaria_plano_estrategico_draftfinal_jan_2012.pdf

4. Mukonka VM, Chanda E, Haque U, Kamuliwo M, Mushinge G, Chileshe J, et al. High burden of malaria following scale-up of control interventions in Nchelenge District, Luapula Province, Zambia. Malar J. 2014; 13:153. doi.org/10.1186/1475-2875-13-153.

5. Louis VR, Schoeps A, Tiendrebéogo J, Beiersmann C, Yé M, Damiba MR, et al. An insecticide-treated bed-net campaign and childhood malaria in burkina faso. Bull World Health Organ. 2015; 93(11):750-758. doi:10.2471/BLT.14.147702.

6. Roberts D, Matthews G. Risk factors of malaria in children under the age of five years old in Uganda. Malar J. 2016; 15:246.doi.org/10.1186/s12936-016-1290-x.

7. Donnelly B, Berrang-Ford L, Labbé J, Twesigomwe S, Lwasa S, Namanya DB, et al. Plasmodium falciparum malaria parasitaemia among indigenous Batwa and non-indigenous communities of Kanungu district, Uganda. Malar J. 2016; 15:254. doi.org/10.1186/s12936-0161299-1.

8. M K, W T, M T, E T, M A. Factors Associated with Malaria Prevalence among Children under Five Years in the Hohoe Municipality of Ghana. J Transm Dis Immun. 2017; 1:2.

9. MISAU-PNCM. Relatório Anual do Programa Nacional de Controlo da Malária (2017). Direcção Nacional de Saúde Pública, Maputo, Moçambique. 2017.

10. Kyu HH, Georgiades K, Shannon HS, Boyle MH. Evaluation of the association between long-lasting insecticidal nets mass distribution campaigns and child malaria in Nigeria. Malar J. 2013; 12: 14. doi.org/10.1186/1475-2875-12-14.

11. Atieli HE, Zhou G, Afrane Y, Lee MC, Mwanzo I, Githeko AK, et al. Insecticide-treated net (ITN) ownership, usage, and malaria transmission in the highlands of western Kenya. Parasites and Vectors. 2011; 4, 113. doi.org/10.1186/1756-3305-4-113.

12. Byakika-Kibwika P, Ndeezi G, Kamya MR. Health care related factors associated with severe malaria in children in Kampala, Uganda. Afr Health Sci. 2009; 9(3):206-210.

13. Yekabong RC, Ebile WA, Fon PN, Asongalem EA. The impact of mass distribution of long lasting insecticide-treated bed-nets on the malaria parasite burden in the Buea Health District in South-West Cameroon: A hospital based chart review of patient's laboratory records. BMC Res Notes. 2017; 10(1):534. doi:10.1186/s13104-017-2870-8.

14. Jagannathan P, Muhindo MK, Kakuru A, Arinaitwe E, Greenhouse B, Tappero J, et al. Increasing incidence of malaria in children despite insecticide-treated bed nets and prompt anti-malarial therapy in Tororo, Uganda. Malar J. 2012; 11:435. doi.org/10.1186/1475-2875-11435.

15. Edelu BO, Ikefuna AN, Emodi Jl, Adimora GN. Awareness and use of insecticide-treated bed nets among children attending outpatient clinic at UNTH, Enugu - the need for an effective mobilization process. Afr Health Sci. 2010; 10(2):117-119;

16. Tobin-West $\mathrm{Cl}$, Alex-Hart BA. Insecticide-treated bednet ownership and utilization in rivers state, Nigeria before a state-wide net distribution campaign. J Vector Borne Dis. 2011; 48(3):133-7.

17. Zgambo M, Mbakaya BC, Kalembo FW. Prevalence and factors associated with malaria parasitaemia in children under the age of five years in Malawi: A comparison study of the 2012 and 2014 Malaria Indicator Surveys (MISs). PLoS One. 2017;

18. Riveron JM, Huijben S, Tchapga W, Tchouakui M, Wondji MJ, Tchoupo M, et al. Escalation of Pyrethroid Resistance in the Malaria Vector Anopheles funestus Induces a Loss of Efficacy of Piperonyl Butoxide-Based Insecticide-Treated Nets in Mozambique. J Infect Dis. 2019; 220(3):467-475.doi: 10.1093/infdis/jiz139.

19. Wanzira H, Katamba H, Okullo AE, Agaba B, Kasule M, Rubahika D. Factors associated with malaria parasitaemia among children under 5 years in Uganda: a secondary data analysis of the 2014 Malaria Indicator Survey dataset. Malar J. 2017; $16(1): 191$.

20. Griffin JT, Déirdre Hollingsworth T, Reyburn H, Drakeley CJ, Riley EM, Ghani AC. Gradual acquisition of immunity to severe malaria with increasing exposure. Proc R Soc B Biol Sci. 2015; 282(1801):20142657. doi: 10.1098/rspb.2014.2657.

21. Barua P, Beeson JG, Maleta K, Ashorn P, Rogerson SJ. The impact of early life exposure to Plasmodium falciparum on the development of naturally acquired immunity to malaria in young Malawian children. Malar J. 2019; 18(1):11. doi: 10.1186/s12936-019-2647-8.

22. Tizifa TA, Kabaghe AN, McCann RS, van den Berg H, Van Vugt M, Phiri KS. Prevention Efforts for Malaria. Current Tropical Medicine Reports. 2018. 5(1): 41-50. doi: 10.1007/s40475-018-0133-y.

23. Afoakwah C, Deng X, Onur I. Malaria infection among children under-five: The use of large-scale interventions in Ghana. BMC Public Health. 2018; doi.org/10.1186/s12889-018-5428-3.

24. Sonko ST, Jaiteh M, Jafali J, Jarju LBS, D’Alessandro U, Camara A, et al. Does socio-economic status explain the differentials in malaria parasite prevalence? Evidence from the Gambia. Malar J. 2014; 13:449. doi: 10.1186/1475-2875-13-449.

Page 10/11 
25. Ruyange MM, Condo J, Karema C, Binagwaho A, Rukundo A, Muyirukazi Y. Factors associated with the non-use of insecticide-treated nets in Rwandan children. Malar J. 2016; doi:10.1186/s12936-016-1403-6

26. Liu JX, Bousema T, Zelman B, Gesase S, Hashim R, Maxwell C, et al. Is housing quality associated with malaria incidence among young children and mosquito vector numbers? Evidence from Korogwe, Tanzania. PLoS One. 2014; 9(2): e87358. doi.org/10.1371/journal.pone.0087358.

27. Wang SJ, Lengeler C, Smith TA, Vounatsou P, Diadie DA, Pritroipa X, et al. Rapid urban malaria appraisal (RUMA) I: Epidemiology of urban malaria in Ouagadougou. Malar J. 2005;

28. Wang SJ, Lengeler C, Mtasiwa D, Mshana T, Manane L, Maro G, et al. Rapid Urban Malaria Appraisal (RUMA) II: Epidemiology of urban malaria in Dar es Salaam (Tanzania). Malar J. 2006; 5, 28. doi.org/10.1186/1475-2875-5-28.

29. Degarege A, Fennie K, Degarege D, Chennupati S, Madhivanan P. Improving socioeconomic status may reduce the burden of malaria in sub Saharan Africa: A systematic review and meta-analysis. PLoS One. 2019; 14(1):e0211205. doi:10.1371/journal.pone.0211205.

\section{Figures}

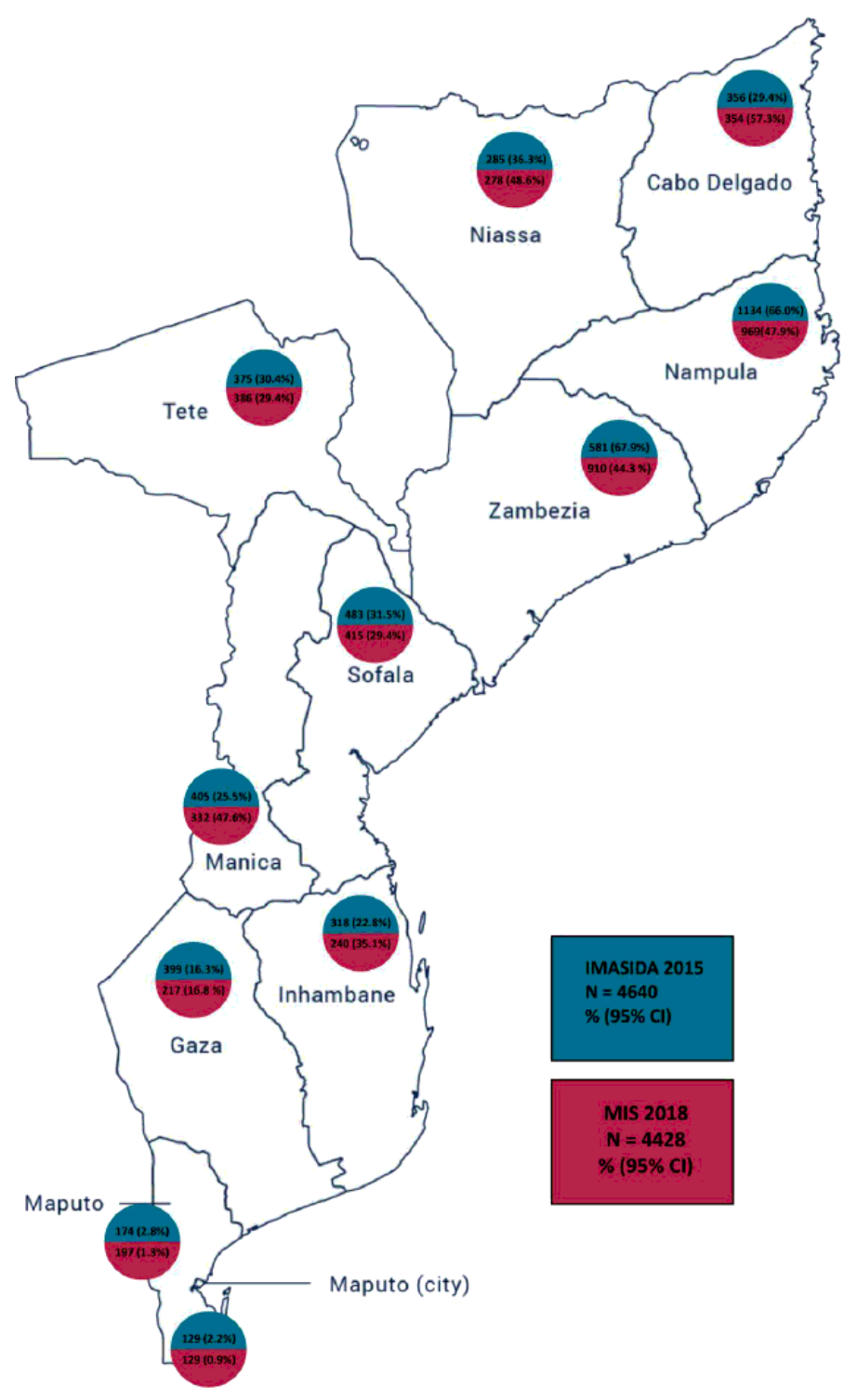

Figure 1

Distribution of malaria prevalence in children 6-59 months old in Mozambique by province, 2015 and 2018 